\title{
Abdominal radical trachelectomy as fertility-sparing management for early stages of cervical cancer: Our experience in 18 cases
}

\author{
SZILARD LEO KISS $^{1}$, ANAS FANDI ${ }^{1}$, ALEXANDRA LAVINIA COZLEA ${ }^{1}$, MIHAI GHEORGHE ${ }^{1}$, MIHAI STANCA ${ }^{1}$, \\ NICOLAE BACALBAȘA ${ }^{2}$, ANDREEA ANAMARIA MOLDOVAN ${ }^{3}$ and MIHAI EMIL CĂPÎLNA ${ }^{1}$ \\ ${ }^{1}$ First Obstetrics and Gynecology Clinic, 'George Emil Palade' University of Medicine, Pharmacy, Science and Technology, \\ 540136 Târgu Mures; ${ }^{2}$ Department of Obstetrics and Gynecology, 'Carol Davila' University of Medicine and Pharmacy, \\ 020022 Bucharest; ${ }^{3}$ Department of Infectious Diseases, Brașov County Emergency Hospital, 500326 Brașov, Romania
}

Received February 16, 2021; Accepted March 18, 2021

DOI: $10.3892 / \mathrm{etm} .2021 .10106$

\begin{abstract}
The aim of this study was to present our experience of 18 cases of abdominal radical trachelectomy (ART), including 5 performed during pregnancy, analyzing patient selection, surgical complications, and oncological and obstetrical outcomes. This reproductive study included all early stage cervical cancer patients referred for ART at the 1st Obstetrics and Gynecology Clinic of the Emergency Clinical County Hospital Targu Mures, between 2010 and 2020. A total of 19 women were considered for ART, and only 1 case required conversion to radical hysterectomy. The patient mean age was 31 years (range 24-38 years), and $66.67 \%$ of the patients were nulliparous. Six women (33.33\%) had stage IA2, 4 (22.22\%) had stage IB1, 5 (27.78\%) had stage IB2, and $4(22.22 \%)$ had stage IB3 disease. One intraoperative complication occurred in this series, which consisted in both right ureteral and bladder injuries. Early postoperative complications were represented by urinary bladder dysfunction (33.33\%), symptomatic pelvic lymphocele $(11.1 \%)$, peritonitis $(5.5 \%)$, and wound infection $(5.5 \%)$. Late postoperative complications included cervical stenosis (5.5\%), amenorrhea (11.1\%), and pelvic abscess (5.5\%). Four out of the 18 patients were operated on during pregnancy between 14 and 20 weeks; 2 of them gave birth at term, 2 of them aborted shortly after the surgery. Two vaginal recurrences were recorded; both were managed by hysterectomy, partial colpectomy and adjuvant chemoradiotherapy. At this moment, all patients are alive with no evidence of disease and 3 of them managed to conceive. In conclusion, ART should be recommended as a fertility-preserving procedure for women
\end{abstract}

Correspondence to: Dr Anas Fandi, First Obstetrics and Gynecology Clinic, 'George Emil Palade' University of Medicine, Pharmacy, Science and Technology, 50 Gheorghe Marinescu, 540136 Târgu Mures, Romania

E-mail: anas_fandi@yahoo.com

Key words: cervical cancer, radical trachelectomy, fertility-sparing, pregnancy, recurrence in their reproductive age. In selected cases, ART can be performed during pregnancy with encouraging results.

\section{Introduction}

Cervical cancer has the 4th highest incidence of all cancers among women in the world. In 2018, approximately 570,000 newly diagnosed cases were registered worldwide. In Central and Eastern Europe, the estimated age-standardized incidence rates for women between 20 and 39 years is 16.2 out of 100,000 (1). This means that a significant proportion of these women will be diagnosed with cervical cancer in their reproductive years. Classical treatment with radical hysterectomy or irradiation therapy unfortunately leads to infertility. Because of the current trend of delayed childbearing, the loss of fertility has a huge psychosocial impact on these patients (2). This has resulted in the need for the development of fertility-sparing procedures in the treatment of cervical cancer.

Vaginal radical trachelectomy (VRT) with laparoscopic pelvic lymphadenectomy was first described by Dargent in 1994 for the treatment of stage IA2 to IIA cervical cancer (3). This procedure presents acceptable oncological outcomes and the best obstetrics outcomes among fertility preserving methods; yet, it requires extensive skill in vaginal and laparoscopic surgery, more training and a longer learning curve (4). In the 1990's, Ungar and Smith 'reinvented' abdominal radical trachelectomy (ART), first described by Aburel in 1956 (5-7). The radicality of the procedure is higher than with the vaginal approach and it is potentially identical to that of the standard type C Querleu-Morrow hysterectomy (8). The obstetrical outcome is slightly worse compared to the vaginal approach, but ART is easier to be learned and it may be used for larger tumors than VRT. That is why it has become the most frequently used radical trachelectomy approach (4). The laparoscopic approach according to recent trials should be avoided because of a higher risk of recurrence and mortality rate and is recommended only for stage IB1 tumors (9).

The aim of this study is to present our experience of 18 cases of ART, including 5 performed during pregnancy, analyzing patient selection, surgical complications, oncological and obstetrical outcomes. 


\section{Patients and methods}

A retrospective study was conducted at the 1st Obstetrics and Gynecology Clinic of the Emergency Clinical County Hospital Targu Mures including all patients who were eligible for fertility-sparing ART procedure for cervical cancer between 2010 to 2020 . The criteria for ART were as follows and as recommended: Histologic diagnosis of invasive cervical cancer (squamous cell carcinoma, adenocarcinoma, or adenosquamous carcinoma), fertile age, a desire for future fertility and no history of infertility, stage IA2 to IB2 (FIGO 2009) disease, and estimated length of the remaining cervix of more than $1 \mathrm{~cm}$ (10). Data were collected from the patients' medical records regarding age, pregnancy history, tumor features, surgical comlpications, oncological and obstetrics outcomes.

All patients underwent a thorough preoperative physical examination as well as routine preoperative testing. Histologic diagnosis resulted from a cervical biopsy or conization. A preoperative transvaginal or transrectal ultrasound plus MRI or CT were performed to assess the tumor size, its local invasion and to evaluate the lymph nodes for all of the patients.

The typical ART technique with ligation of uterine arteries (excep for ART performed during pregnancy, when at least one uterine artery is preserved), preservation of ovarian vessels, a bilateral parametrectomy corresponding to type $\mathrm{C}$ radical hysterectomy in the classification published by Querleu and Morrow, and a pelvic lymphadenectomy was carried out (8). After midline laparotomy, a pelvic lymphadenectomy was performed up to the deep circumflex iliac vein caudally, and the aortic bifurcation cephalad. If no suspicious lymph nodes were detected, the radical abdominal trachelectomy was initiated by developing the pararectal and paravesical spaces. Bilateral parametrectomy was then performed to the level of the pelvic sidewall. The uterosacral ligament was divided, after the recto-vaginal space was created by blunt dissection, and finally the anterior parametria was resected, after ureterolysis. After the incision of the vagina, the specimen was extracted from the pelvis, and the radical trachelectomy was completed by separating the cervix from the isthmus at approximately $1 \mathrm{~cm}$ below the level of the internal os. A discoid histologic specimen harvested from the lower part of the remaining isthmus was sent for frozen section; if the specimen was confirmed to be tumor-positive, a radical hysterectomy was immediately carried out. To re-establish the continuity of the reproductive tract, six to eight interrupted, or a continuous absorbable suture was placed from the vagina to the lower uterus in a circumferential manner. A careful pelvic peritonization was performed at the end of the procedure, with the goal to ensure best anatomical and healing conditions for an eventually spontaneous pregnancy (11). Apart from the ART performed during pregnancy, a permanent cerclage was not considered useful.

Postoperatively, the patients were followed up every 3 months for the first 2 years, then every 6 months for the next 3 years, and annually thereafter; with clinical examination, transvaginal ultrasound, Papanicolaou test and by abdominal CT or MRI annually. All women were advised to postpone a pregnancy for a minimum of 6 months after ART, with at least 2 consecutive normal Papanicolaou smears.

\section{Results}

Between 2010 and 2020, a total of 19 cervical cancer patients were referred for ART to our institution. In one patient, ART was converted to radical hysterectomy because of the presence of a tumor-positive lower isthmus specimen upon frozen section.

Thus, ART was completed in 18 patients. The median patient age was 31 (range, 24-38 years); 12 (66\%) were nulliparous. The patient characteristics are listed in Table I.

Based on the International Federation of Gynecology and Obstetrics clinical staging system (FIGO 2018), 6 (33.33\%) were in stage IA2, $4(22.22 \%)$ in stage IB1, $5(27.78 \%)$ in stage IB2, and $4(22.22 \%)$ in stage IB3 disease. Lymphovascular space invasion (LVSI) was described in $10(55.55 \%)$ patients. The median tumor size was $22 \mathrm{~mm}$ (range, 6-49 $\mathrm{mm}$ ). In 9 cases (50\%) the tumor was larger than $2 \mathrm{~cm}$. Histologic subtypes included: 15 (83.33\%) squamous carcinomas, 2 (11.11\%) adenocarcinomas, and $1(5.55 \%)$ glassy cell adenocarcinoma. The mean number of lymph nodes removed during surgery was 38 (range, 13-58).

One intraoperative complication occurred in this series, which consisted in both right ureteral and bladder injuries. Suprapubic cystostomy with bladder suturing and ureteral resection with termino-terminal ureteral anastomosis on double $\mathrm{J}$ stent was carried out without any postoperative complication. The postoperative complications are summarized in Table II. In the postoperative period, bladder dysfunction occurred for more than 7 days in 6 out of 18 definitive ART patients (33.3\%) which were solved by prolonged catheterization and bladder exercises. Two cases of infected pelvic lymphoceles (11.1\%) were drained under ultrasound guidance, and an abdominal wound infection in one case required re-suturing. Two patients had positive pelvic lymph nodes on final pathology results and were sent for chemoradiation, becoming menopausal.

Five patients were operated on during pregnancy as shown in Table III. The surgery was carried out between 14 and 20 weeks. In two cases, postoperative recovery was complicated by rupture of the amniotic membranes followed by spontaneous abortion in the first 10 days after surgery, despite tocolytic, antibiotic and progesterone treatment. One of these 2 patients developed general peritonitis on the 11th postoperative day and she was re-operated and drained, but with preservation of the uterus and both adnexae, with complete recovery afterwards. The other two patients later experienced an uneventful pregnancy and reached full term; they both delivered two healthy babies by elective Caesarean section.

In one case, the surgery consisted of 2 steps. First, a Caesarean section was performed at 32 weeks of pregnancy, followed immediately by an ART with pelvic lymphadenectomy. The patient was diagnosed with stage IB2 cervical cancer at 24 weeks of pregnancy. She was sent for neoadjuvant chemotherapy, but the medical oncologist denied administering the treatment because of elevated liver enzymes. The patient refused termination of the pregnancy and finally both obstetrical and oncological management was chosen after informed consent.

Most patients did not experience late postoperative complications. One of them (5.5\%) had clinically notable cervical stenosis and required cervical dilation. Another two patients became amenorrheic, probably due to insufficient uterine vascularization through the ovarian vessels after ligation of 
Table I. Patient characteristics of the ART cases $(\mathrm{N}=18)$.

\begin{tabular}{lc}
\hline Characteristics & Data \\
\hline Age, years, Median (range) & $31(22-38)$ \\
Pregnancy history, n (\%) & \\
Nullipara & $12(66.67)$ \\
Primipara & $4(22.22)$ \\
Multipara & $2(11.11)$ \\
FIGO 2018 stage, n (\%) & \\
IA2 & $6(33.33)$ \\
IB1 & $4(22.22)$ \\
IB2 & $5(27.78)$ \\
IB3 & $4(22.22)$ \\
Histology, n (\%) & \\
Squamous cell carcinoma, total & $15(83.33)$ \\
GR1 & $1(5.55)$ \\
GR2 & $8(44.44)$ \\
GR3 & $6(33.33)$ \\
Adenocarcinoma & $2(11.11)$ \\
Glassy cell adenocarcinoma & $1(5.55)$ \\
LVSI, n (\%) & \\
Yes & $10(55.56)$ \\
No & $82.31(6-49)$ \\
Tumor size mm, mean (range) & \\
<2 cm & $9(50)$ \\
\hline
\end{tabular}

ART, abdominal radical trachelectomy; LVSI, lymphovascular space invasion.

both uterine arteries. Another patient developed a pelvic abscess one year after ART, possibly because of the removal of the cervix, and a left adnexectomy was performed.

To date, 2 patients developed recurrences, both located on the superior part of the vagina. One recurrence occurred after 10 months, and the second 8 years after ART. Hysterectomy and partial colpectomy were performed in both patients, followed by adjuvant chemoradiotherapy. At present, all 18 patients who underwent ART, including the 2 with recurrences, are alive and free of disease.

Regarding the obstetrical outcome, except the two patients with amenorrhea and the two who were menopausal after chemoradiation, 7 out of the remaining 14 women reported a desire to conceive during the follow-up period. Three out of $7(42.8 \%)$ women were successful in conceiving: There were 5 live births at term, all by elective Caesarean section, and no miscarriages or preterm births in our series. Two patients had 2 pregnancies each. Among the total number of ART patients, the pregnancy rate was $16.6 \%$.

\section{Discussion}

When considering abdominal radical trachelectomy (ART) as a fertility-sparing procedure aimed to treat an oncological
Table II. Surgical, oncological and reproductive outcomes of the ART cases.

\begin{tabular}{lc}
\hline Outcomes & Data \\
\hline $\begin{array}{l}\text { No. of lymph nodes retrieved, } \\
\text { median (range) }\end{array}$ & $38(13-58)$ \\
Intraoperative complications & 1 (bladder \\
& $\begin{array}{c}\text { and right } \\
\text { ureteral injury) }\end{array}$ \\
Early postoperative complications, $\mathrm{n}(\%)$ & \\
Urinary bladder dysfunction & $6(33.3)$ \\
Pelvic lymphoceles & $2(11.1)$ \\
Pelvic peritonitis & $1(5.5)$ \\
Wound infection & $1(5.5)$ \\
Late postoperative complications, $\mathrm{n}(\%)$ & $1(5.5)$ \\
Cervical stenosis & $2(11.1)$ \\
Amenorrhea & $1(5.5)$ \\
Pelvic abscess & \\
Oncological outcomes, $\mathrm{n}(\%)$ & $2(11.1)$ \\
Recurrences & $16(88.8)$ \\
Free of disease & \\
Obstetric outcomes & $3 / 7$ trying to \\
Pregnancies after ART & conceive \\
& $(42.8 \%)$ \\
\hline
\end{tabular}

ART, abdominal radical trachelectomy.

disease, it is important to find an appropriate balance between oncological radicality and obstetrical outcomes. A proper selection of patients, including the above-mentioned clinical imaging techniques can help to optimize postoperative results.

In well selected populations, the recurrence rate and mortality rate can be as low as 3.8 and $0.4 \%$, respectively, according to a systematic review of the literature analyzing 485 patients subjected to fertility-sparing procedures (12).

There is a debate concerning the oncological safety of this procedure in the case of tumors larger than $2 \mathrm{~cm}$. Unfortunately, a considerable proportion of patients have larger tumors at the time of diagnosis. In our series as well, one half of the patients who desired the preservation of fertility had tumors larger than $2 \mathrm{~cm}$. Our data show good oncologic outcomes with low recurrence rates. This finding is also confirmed by a Hungarian study which reports a 5-year disease-free survival of $87.1 \%$ for women with tumour size greater than $2 \mathrm{~cm}$ treated with ART (13). In addition, in a Chinese retrospective study on 333 ART patients, the recurrence rate for tumors larger than $2 \mathrm{~cm}$ was similar to that for smaller tumours $<2 \mathrm{~cm}$. But the recurrence rate was lower for squamous cell carcinoma and adenocarcinoma histology compared to adenosquamous cancer (3.9, 2.6 and 18.2\%, respectively, $\mathrm{P}<0.05)$. Tumor histology was shown to be the only independent recurrence risk factor after multivariate analysis (14).

For stage IB2 (FIGO 2018) cervical cancer (tumor $\geq 2 \mathrm{~cm}$ but $<4 \mathrm{~cm})$, two fertility-sparing approaches were studied in a 
Table III. Cases for which ART was performed during pregnancy.

\begin{tabular}{|c|c|c|c|c|c|c|c|c|c|}
\hline & $\begin{array}{l}\text { GA at, } \\
\text { surgery } \\
\text { weeks }\end{array}$ & $\begin{array}{c}\text { Stage } \\
\text { (tumor size } \\
\text { in } \mathrm{mm} \text { ) }\end{array}$ & Histology & $\begin{array}{l}\text { Status of } \\
\text { the uterine } \\
\text { arteries }\end{array}$ & $\begin{array}{l}\text { Duration } \\
\text { of surgery }\end{array}$ & $\begin{array}{l}\text { Estimated } \\
\text { blood loss }\end{array}$ & $\begin{array}{c}\text { Pregnancy } \\
\text { outcome }\end{array}$ & $\begin{array}{l}\text { Neonatal } \\
\text { outcome }\end{array}$ & $\begin{array}{c}\text { Oncological } \\
\text { outcome }\end{array}$ \\
\hline Case 1 & 16 & IB2 (37) & $\begin{array}{l}\text { Squamous } \\
\text { GR3 }\end{array}$ & $\begin{array}{l}\text { Left } \\
\text { ligated }\end{array}$ & $290 \mathrm{~min}$ & $500 \mathrm{ml}$ & $\begin{array}{l}\text { CS-38 } \\
\text { weeks }\end{array}$ & Good & NED \\
\hline Case 2 & 15 & IB3 (49) & $\begin{array}{l}\text { Squamous } \\
\text { GR2 }\end{array}$ & $\begin{array}{l}\text { Both } \\
\text { preserved }\end{array}$ & $320 \mathrm{~min}$ & $800 \mathrm{ml}$ & $\begin{array}{l}\text { AB-9th } \\
\text { postop day }\end{array}$ & - & NED \\
\hline Case 3 & 14 & IB3 (43) & $\begin{array}{l}\text { Squamous } \\
\text { GR3 }\end{array}$ & $\begin{array}{l}\text { Both } \\
\text { preserved }\end{array}$ & $350 \mathrm{~min}$ & $500 \mathrm{ml}$ & $\begin{array}{l}\text { AB-12th } \\
\text { postop day }\end{array}$ & - & $\begin{array}{l}\text { Adjuvant chemo } \\
\text { radiation for } \\
\text { positive lymph } \\
\text { nodes } \\
\text { NED }\end{array}$ \\
\hline Case 4 & 20 & IB3 (45) & $\begin{array}{l}\text { Squamous } \\
\text { GR3 }\end{array}$ & $\begin{array}{l}\text { Left } \\
\text { ligated }\end{array}$ & $310 \mathrm{~min}$ & $700 \mathrm{ml}$ & $\begin{array}{l}\text { CS-39 } \\
\text { weeks }\end{array}$ & Good & NED \\
\hline Case 5 & 32 & IB3 (45) & $\begin{array}{l}\text { Squamous } \\
\text { GR2 }\end{array}$ & $\begin{array}{l}\text { Both } \\
\text { ligated }\end{array}$ & $300 \mathrm{~min}$ & $700 \mathrm{ml}$ & $\begin{array}{l}\text { CS-32 } \\
\text { weeks prior } \\
\text { to ART }\end{array}$ & Good & NED \\
\hline
\end{tabular}

ART, abdominal radical trachelectomy; AB, abortion; CS, Cesarean section; GA, gestational age; NED, no evidence of disease.

meta-analysis on 338 patients: i) neoadjuvant chemotherapy (NACT) followed by vaginal radical trachelectomy (VRT) plus pelvic lymphadenectomy either before neoadjuvant chemotherapy or at the time of VRT; ii) ART plus pelvic lymphadenectomy. After chemotherapy followed by VRT, $70 \%$ of the women who tried to conceive became pregnant. The recurrence rate was $10 \%$ and mortality $2.9 \%$. After ART, $21 \%$ of women who have tried to conceive became pregnant. Recurrence rate was $6.9 \%$, and overall mortality $3.4 \%$. In conclusion, VRT preceded by neoadjuvant chemotherapy exhibited better obstetrical outcomes compared to ART, with similar oncological results (15).

In non-pregnant women, cerclage was avoided at the end of ART, despite the recommendations of other authors (16). As described by Aburel, the scar tissue developed on the remaining cervix-istmus after ART would be strong enough to prevent an abortion (5). This may be the explanation for the low incidence of cervical stenosis in our study (5.5\%), compared with other studies $(9.5-12 \%)(12,17)$. By contrast, a prophylactic cerclage was performed in all ART during pregnancy.

Our pregnancy rate $(16.6 \%)$ was similar to that described by Okugawa et al-18\% for patients with tumor dimension $<2 \mathrm{~cm}$ and $8.1 \%$ for larger tumors and Pareja et al-16.2\% $(12,18)$. All of our ART patients delivered at term, despite avoiding the cerclage during ART. The premature delivery rate may be as high as $60 \%$ in other studies because of the shortened cervix $(12,17,19)$. After VRT, a significantly higher rate of pregnancy is observed compared with ART, 57 vs. 44\%, but without any difference in the live birth rate (19).

The occurrence of late complications after ART can significantly alter the quality of life. A recent study highlighted overall low baseline and follow-up scores on the Female Sexual Functioning Index suggesting overall sexual dysfunction. Quality of life, sexual, and functional assessments declined immediately postoperatively; however, most returned to baseline measures by 6 months postoperatively (20).
Recognizing patients with a high risk for developing complications is of great importance. Li et al observed a correlation between the abdominal scar characteristics using the Vancouver Scar Scale (VSS) and the risk of developing cervical stenosis. They suggest the placement of a tailed IUD at the time of surgery, and keeping it in place until the patient wishes to conceive for all the patients with VSS score $>7$ (21).

A challenge for performing ART is the preservation of one or both uterine arteries to ensure a sufficient blood supply to the uterus (22). Initial description of the procedure involved the ligation of both uterine arteries (5). This approach raises concerns regarding possible uterine atrophy and/or amenorrhea and consecutively to a negative impact on fertility (cervical stenosis) and obstetric outcomes (prematurity, low birth weight). Reports concerning the preservation of uterine vessels are scarce, excepting for ART performed during pregnancy, when the uterine artery size is larger $(23,24)$. The main concern regarding the oncologic radicality is related to the ability to perform an identical type $\mathrm{C}$ parametrectomy without the ligation of the uterine vessels, which technically is more difficult.

Out of our 18 ART cases, 5 patients were operated on during pregnancy, between 2015 and September 2019. ART was performed in the second trimester in 4 out of the 5 patients, out of which 2 patients aborted during the first 10 days after the procedure due to premature rupture of membranes, and the other 2 had a no-eventful pregnancy and delivered by elective C-section at term (Table III). The fifth ART case was performed at 32 weeks of pregnancy and consisted of two steps: First, an elective C-section, followed by ART. All the five patients are free of disease at this moment, but one of them, after abortion, was sent for chemoradiation for positive lymph nodes on final pathology report. However, ART might be considered for appropriately selected patients with early-stage cervical 
cancer having a strong desire to preserve their pregnancy and who are not willing to expose the fetus to the risks that may arise due to neoadjuvant chemotherapy (25). The early second trimester of pregnancy appears to be the most suitable period during which to carry out this procedure (26).

Performing ART is not a guarantee for a successful upcoming pregnancy; on the contrary, it can lead to pregnancy complications. Preoperative counseling regarding unfavorable obstetrical outcome is very important and can also help to set realistic expectations regarding pregnancy. In order to correctly identify the cause of infertility after ART, a preoperative assessment of the reproductive capability (ovarian reserve, ovulatory dysfunction or tubal factor) is recommended by a reproductive specialist (27). ART is a demanding technique; thus, it is advisable for this procedure to be performed only at oncologic departments with high expertise in cervical cancer surgery, that are extremely familiar in performing radical hysterectomies (28).

In conclusion, abdominal radical trachelectomy should be recommended as a fertility-preserving procedure for women in their reproductive age. A proper selection of patients and the suitable radical trachelectomy approach (abdominal, vaginal or laparoscopic) can help to optimize postoperative results (29). An optimal balance between the extent of surgical therapy and the patient's desire to maintain their fertility should be targeted. Shared decision making and detailed informed consent are essential.

\section{Acknowledgements}

Not applicable.

\section{Funding}

No funding was received.

\section{Availability of data and materials}

The datasets used during the current study are available from the corresponding author on reasonable request.

\section{Authors' contributions}

Conception and design of the study were carried out by SLK, AF, NB, ALC and MEC. Acquisition of data was carried out by SLK, AF, MG, ALC and MS. Interpretation of the data was performed by SLK, AF, MG, ALC, MEC and AAM. Drafting of the manuscript was conducted by SLK, AF and ALC. Revising the manuscript critically for important intellectual content was carried out by MEC and AAM. All authors read and approved the final manuscript.

\section{Ethics approval and consent to participate}

The approval of the Ethics Committee of the Emergency County Hospital of Târgu Mures was obtained (No. 32647). Patient identifying information, including names, initials, date of birth, or hospital numbers are not included in the manuscript. Because of the retrospective nature of the study informed consent of patients was not required.

\section{Patient consent for publication}

Not applicable.

\section{Competing interests}

The authors declare that they have no competing interests.

\section{References}

1. Ferlay J, Ervik M, Lam F, Colombet M, Mery L and Piñeros M: Global Cancer Observatory: Cancer Today. Lyon, France: International Agency for Research on Cancer. Available from: https://gco.iarc.fr/today. Accessed October 16, 2020.

2. Wenzel L, De Alba I, Habbal R, Kluhsman BC, Fairclough D, Krebs LU, Anton-Culver H, Berkowitz R and Azizet N: Quality of life in long-term cervical cancer survivors. Gynecol. Oncol 97: 310-317, 2005.

3. Dargent D, Martin X, Sacchetoni A and Mathevet P: Laparoscopic vaginal radical trachelectomy: A treatment to preserve the fertility of cervical carcinoma patients. Cancer 88: 1877-1882, 2000.

4. Plante M: Evolution in fertility-preserving options for early-stage cervical cancer: Radical trachelectomy, simple trachelectomy, neoadjuvant chemotherapy. Int J Gynecol Cancer 23: 982-989, 2013.

5. Capilna ME, Ioanid N, Scripcariu V, Gavrilescu MM and Szabo B: Abdominal radical trachelectomy: A Romanian series. Int J Gynecol Cancer 24: 615-619, 2014.

6. Ungár L, Pálfalvi L, Hogg R, Siklós P, Boyle DC, Del Priore G and Smith JR: Abdominal radical trachelectomy: A fertility-preserving option for women with early cervical cancer. BJOG 112: 366-369, 2005.

7. Smith JR, Boyle DC, Corless DJ, Ungar L, Lawson AD, Priore GD, McCall JM, Lindsay I and Bridges JE: Abdominal radical trachelectomy: A new surgical technique for the conservative management of cervical carcinoma. BJOG 104: 1196-1200, 1997.

8. Querleu D and Morrow CP: Classification of radical hysterectomy. Lancet Oncol 9: 297-303, 2008.

9. Chiva L, Zanagnolo V, Querleu D, Martin-Calvo N, ArévaloSerrano J, Căpîlna ME, Fagotti A, Kucukmetin A, Mom C, Chakalova G, et al: SUCCOR study: An international European cohort observational study comparing minimally invasive surgery versus open abdominal radical hysterectomy in patients with stage IB1 cervical cancer. Int J Gynecol Cancer 30: 1269-1277, 2020

10. Schneider A, Erdemoglu E, Chiantera V, Reed N, Morice P, Rodolakis A, Denschlag D and Kesic V: Clinical recommendation radical trachelectomy for fertility preservation in patients with early-stage cervical cancer. Int J Gynecol Cancer 22: 659-666, 2012

11. Căpîlna ME, Rusu SC, Puiac CI, Daniilidis A and Szabo B: Spontaneous intrauterine pregnancy following abdominal radical trachelectomy-a case report. Eur J Gynaecol Oncol 36: 229-230, 2015.

12. Pareja R, Rendón GJ, Sanz-Lomana CM, Monzón O and Ramirez PT: Surgical, oncological, and obstetrical outcomes after abdominal radical trachelectomy-a systematic literature review. Gynecol Oncol 131: 77-82, 2013.

13. Lintner B, Saso S, Tarnai L, Novak Z, Palfalvi L, Del Priore G, Smith JR and Ungar L: Use of abdominal radical trachelectomy to treat cervical cancer greater than $2 \mathrm{~cm}$ in diameter. Int J Gynecol Cancer 23: 1065-1070, 2013.

14. Li X, Li J, Jiang Z, Xia L, Ju X, Chen X and Wu X: Oncological results and recurrent risk factors following abdominal radical trachelectomy: An updated series of 333 patients. BJOG 126: 1169-1174, 2019.

15. Van Kol KG, Vergeldt TF and Bekkers RL: Abdominal radical trachelectomy versus chemotherapy followed by vaginal radical trachelectomy in stage 1B2 (FIGO 2018) cervical cancer. A systematic review on fertility and recurrence rates. Gynecol Oncol 155: 515-521, 2019.

16. Lewin SN and Abu-Rustum NR: Fertility-sparing radical abdominal trachelectomy for cervical cancer. In: Atlas of Procedures in Gynecologic Oncology. 2nd edition. Levine DA, Barakat RR and Abu-Rustum NR (eds). Informa Healthcare, London, pp129-136, 2008. 
17. Wethington SL, Cibula D, Duska LR, Garrett L, Kim CH, Chi DS, Sonoda Y and Abu-Rustum NR: An international series on abdominal radical trachelectomy: 101 patients and 28 pregnancies. Int J Gynecol Cancer 22: 1251-1257, 2012.

18. Okugawa K, Yahata H, Sonoda K, Ohgami T, Yasunaga M, Kaneki E and Kato K: Safety evaluation of abdominal trachelectomy in patients with cervical tumors $\geq 2 \mathrm{~cm}$ : A single-institution, retrospective analysis. J Gynecol Oncol 31: e41, 2020.

19. Bentivegna E, Maulard A, Pautier P, Chargari C, Gouy S and Morice P: Fertility results and pregnancy outcomes after conservative treatment of cervical cancer: A systematic review of the literature. Fertil Steril 106: 1195-1211, 2016.

20. Fleming ND, Ramirez PT, Soliman PT, Schmeler KM, Chisholm GB, Nick AM, Westin SN and Frumovitz M: Quality of life after radical trachelectomy for early-stage cervical cancer: A 5-year prospective evaluation. Gynecol Oncol 143: 596-603, 2016.

21. Li X, Li J, Ju X, Chen X and Wu X: Abdominal scar characteristics as a predictor of cervical stenosis after abdominal radical trachelectomy. Oncotarget 7: 37755-37761, 2016.

22. Căpîlna ME, Szabo B, Rusu SC, Becsi J and Neagoe RM: Anatomical variations of the obturator veins and their surgical implications. Eur J Gynaecol Oncol 38: 263-265, 2017.

23. Yoo S, Terai Y, Tanaka T, Tanaka Y, Tsunetoh S, Kanemura M and Ohmichi M: Role of the two-point pull-up technique for treating the uterine arteries during radical hysterectomy and trachelectomy. Eur J Obstet Gynecol Reprod Biol 170: 544-549, 2013

24. Wan XP, Yan Q, Xi XW and Cai B: Abdominal radical trachelectomy: Two new surgical techniques for the conservation of uterine arteries. Int J Gynecol Cancer 16: 1698-1704, 2006.
25. Stanca M, Ciobanu V, Gheorghe M, Kiss SL, Cozlea AL and Căpîlna ME: The double life-saving approach of abdominal radical trachelectomy during pregnancy for early-stage cervical cancer-an overview of the literature and our institutional experience. J Pers Med 11: 29, 2021.

26. Douligeris A, Prodromidou A, Psomiadou V, Iavazzo C and Vorgias G: Abdominal radical trachelectomy during pregnancy: A systematic review of the literature. J Gynecol Obstet Hum 49: 101607, 2020.

27. Shah JS, Jooya ND, Woodard TL, Ramirez PT, Fleming ND and Frumovitz M: Reproductive counseling and pregnancy outcomes after radical trachelectomy for early stage cervical cancer. J Gynecol Oncol 30: e45, 2019.

28. Căpîlna ME, Moldovan B and Szabo B: Pelvic exenteration-our initial experience in 15 cases. Eur J Gynaecol Oncol 36: 142-145, 2015.

29. Salvo G, Ramirez PT, Leitao M, Cibula D, Fotopoulou C, Kucukmetin A, Rendon G, Perrotta M, Ribeiro R, Vieira M, et al: International radical trachelectomy assessment: IRTA study. Int J Gynecol Cancer 29: 635-638, 2019.

This work is licensed under a Creative Commons Attribution-NonCommercial-NoDerivatives 4.0 International (CC BY-NC-ND 4.0) License. 